\title{
Qualitative Research in Nursing and Health Professions Regulation
}

\author{
Allison Squires, PhD, RN, FAAN, and Caroline Dorsen, PhD, FNP, RN
}

\begin{abstract}
Qualitative research is critical for studies about regulatory issues in nursing and across all health professions. When indepth stakeholder perspectives are needed, qualitative approaches are often the best methodological choice to ensure their viewpoints and experiences are captured when evaluating the consequences of policy implementation or when informing regulation design. Unlike traditional qualitative health care studies that involve patients or providers in single settings, regulatory studies often have complex challenges related to the available sample sizes, sampling strategies, and data collection approaches. Reporting qualitative findings in ways that are informative, useful, and dialogue provoking about regulatory issues must go beyond inserting long quotes with a single sentence explanation. Artfully capturing the participants' stories within the regulatory matter under study is vital for understanding potential and actual consequences of regulations. This article provides an overview of common methodological challenges researchers encounter when conducting qualitative research on professional regulation issues and offers solutions to enhance the quality, rigor, and trustworthiness of the findings. The recommendations may prove useful to researchers examining regulatory issues in nursing and other health professions.
\end{abstract}

Keywords: Credentialing, government regulation, licensure, policy, professional autonomy, qualitative research

\section{Objectives}

- Explain the importance of qualitative research for studies about regulatory issues in nursing.

- Discuss the core concepts of qualitative research.

- Describe common methodological challenges researchers can encounter when conducting qualitative research on professional regulatory issues.

- Identify solutions that can enhance the quality, rigor, and trustworthiness of the findings for regulatory studies.

$\mathrm{H}$ ealth profession regulation is defined as the local and national government oversight needed for professional practice to avoid a risk of harm to the public if practiced by an unprepared or incompetent person. In this paper, we use "regulation" to refer to any activities related to this definition.

Whether examining the consequences of regulations on stakeholders or bringing their voice into the development of regulations around health issues-patient safety, credentialing, competency, scope of practice, transitions to practice, disciplinary actions, etc. - qualitative research is critical for providing exploratory and explanatory data in concert with quantitative results. Qualitative research plays an important role in ensuring the stakeholders' voices are represented and their experiences inform the evaluation of regulations and associated policies when studying nursing and other health professions (Blackman, Wistow, \& Byrne, 2013; Bradley, Curry, \& Devers, 2007; Evans-Agnew,
Johnson, Liu, \& Boutain, 2016; Griffith, Shelton, \& Kegler, 2017). On its own and with sufficient replication, qualitative research can provide supporting evidence for the creation, modification, or elimination of regulations.

As qualitative research evolved over the past four decades, standards for rigor and trustworthiness have grown (Bartlam et al., 2016; Caelli, Ray, \& Mill, 2003; Saunders et al., 2018; Tufford \& Newman, 2012; Vandermause et al., 2016; Yardley, Watts, Pearson, \& Richardson, 2014). Subsequently, the quantity and quality of qualitative research studies published in most health care journals have increased substantially. New methodological advancements around minimum sample sizes, sampling strategies, and techniques for integrating mixed-methods studies are advancing this approach to research. Qualitative research in the 21 st century plays a critical role in solidifying the evidencebase and foundation for quantitative studies.

Despite the need for solid qualitative evidence on regulatory topics, the Journal of Nursing Regulation receives few qualitative studies of sufficient rigor and trustworthiness to merit publication. A review of published studies shows that in the near decade since the journal's inception, only 12 qualitative studies have been published as compared to over 300 quantitative studies, which is less than $5 \%$ of the evidence overall. In an effort to encourage high-quality qualitative submissions on regulatory issues, this article provides an overview of common methodological challenges researchers may encounter when conducting qualitative research on nursing and health profession regulation issues. 


\section{A Review of Core Qualitative Research Concepts}

Qualitative studies have historically been derided for their analyses because most researchers did not understand standards for qualitative research rigor (Bochner, 2018). To meet this need, experts developed and refined four key concepts to help ensure the rigor of qualitative research findings.

Rigor in qualitative research is defined as how the researcher establishes the trustworthiness of the findings (Morse, 2015). Rigorous qualitative research reflects how well the study was implemented and managed unforeseen circumstances. It has four, well-established dimensions that have equivalent conceptual counterparts in quantitative research. Table 1 provides the definitions and equivalent quantitative terms for establishing rigor in qualitative research studies. While Morse (2015) argues that qualitative and quantitative terminology for rigor should use the same terms, the qualitative specific terms for rigor were developed over 30 years ago and have shaped the field's language. Thus, for most qualitative studies, demonstrating explicitly or implicitly how the researcher ensured the rigor of the study is an important part of the dissemination process. Tracy's (2010) eight criteria for "excellent" qualitative research also offer authors clear guidance for enhancing the rigor of their studies.

Part of ensuring rigor in any research study is mitigating bias. Bias is an important concept for qualitative research because it pertains to the central concern about the possible influence of the ideas and opinions of the researchers conducting the research study. For example, how does the reader know the researchers maintained as much objectivity as possible during the interview process? How much do the readers know about the process of results analysis? Mitigating bias is an important part of the analysis process of qualitative data. Bias in qualitative research occurs when researchers ask leading questions during interviews or impose views during the analysis process, guiding the findings to reflect their own beliefs instead of staying objective. It is the same phenomenon as when quantitative researchers stretch statistical analyses to obtain the results they want rather than the true results. Additionally, mitigating bias helps ensure study reproducibility, which is an important concern for most funding bodies.

Qualitative rigor is also established through data saturation. Data saturation occurs when a researcher has conducted enough interviews that no new information is being gathered from participants (Patton, 2015). It is often underreported in most published qualitative studies. Data saturation is an important concept in qualitative research because it indicates when no additional interviews are needed and data collection can end. Poorly planned qualitative studies, for example, budget only for a certain number of interviews and assume data saturation will happen within that number, rather than continuing the study until data saturation is achieved. In effect, data saturation happens within a range of participants (Hennink, Kaiser, \& Marconi,
2017; Saunders et al., 2018). Sample homogeneity vs. heterogeneity, contextual factors, and the complexity of the phenomenon of interest can all influence when data saturation occurs.

The final rigor-related core concept in qualitative research is trustworthiness. For research findings to be trustworthy, they need to meet the four criteria associated with research rigor, and they should have a common truth that resonates with individuals with similar experiences.

An additional step to help authors illustrate the rigor of their studies is to use a critical appraisal checklist. Majid and Vanstone (2018) reviewed the strengths and limitations of eight qualitative-focused critical appraisal checklists. When preparing a qualitative manuscript, a checklist can assist researchers with organization of the paper and help ensure all required content is included.

\section{A Note on Cross-language Qualitative Research on Regulatory Issues}

In international studies or those with stakeholders who may not speak the same language as the researcher, it is critically important for researchers to systematically manage language barriers between participants and themselves. Language translation places data at risk for semantic, conceptual, technical, and contentrelated issues due to potential translation errors (Squires, 2008). For qualitative data, poorly translated interview data mean findings become untrustworthy, or, as in the quantitative lexicon, not reliable or valid (Squires, 2009). Using qualified interpreters, multi-language coding processes, and independent checks on the translation and coding processes can help lessen these risks (Chapple \& Ziebland, 2018; Chiumento, Rahman, Machin, \& Frith, 2017; Croot et al., 2011; Lincoln, Gonzalez y Gonzalez, \& Aroztegui Massera, 2016; MacKenzie, 2015; Santos, Black, \& Sandelowski, 2014; Suurmond, Woudstra, \& Essink-Bot, 2016; Temple, 2002; Wong \& Poon, 2010).

\section{An Overview of Qualitative Study Designs Appropriate for Regulatory Studies}

A qualitative approach to research is not a design in and of itself. Like quantitative research, there are different types of qualitative study designs that inform study implementation, sampling approach, analysis, and study goal. For regulatory studies, some approaches may be more appropriate than others. Table 2 provides an overview of different types of qualitative study designs and highlights their strengths and limitations in regulatory studies (Patton, 2015).

Choosing the appropriate study design for a regulatory issue is the most important first step a researcher can take to generate a study that provides quality evidence (Carter \& Little, 2007). The qualitative study designs most researchers are familiar with—grounded theory, phenomenology, qualitative descriptive-all have merits for studying regulatory issues. Ethnography, 
TABLE 1

\section{Equivalent Concepts of Rigor in Qualitative vs. Quantitative Research}

\begin{tabular}{|c|c|c|}
\hline $\begin{array}{l}\text { Qualitative } \\
\text { Rigor Concept }\end{array}$ & $\begin{array}{l}\text { Determined by One or More of the Following Actions by Researchers } \\
\text { (Krefting, 1991; Lincoln \& Guba, 1985; Morse, 2015) }\end{array}$ & $\begin{array}{l}\text { Equivalent Term for } \\
\text { Quantitative Research }\end{array}$ \\
\hline Credibility & $\begin{array}{l}\text { - Prolonged engagement with the data } \\
\text { - Persistent observation } \\
\text { - Triangulation of data across participants } \\
\text { - Peer debriefing } \\
\text { - Negative case analysis } \\
\text { - Referential adequacy } \\
\text { - Member checks } \\
\text { - Accuracy of the findings overall } \\
\text { Did the participants find the presentation of the results a "truthful" representation of } \\
\text { their experiences? }\end{array}$ & Internal validity \\
\hline Transferability & $\begin{array}{l}\text { - Thick description of the results is provided through a combination of exemplar quotes } \\
\text { and critical analysis of the findings in relation to the original research question. } \\
\text { - The reader can see how findings would apply in another context with a similar group } \\
\text { of participants with minimal variation. }\end{array}$ & $\begin{array}{l}\text { External validity/ } \\
\text { generalizability }\end{array}$ \\
\hline Confirmability & $\begin{array}{l}\text { - Strategies of triangulation during data analysis to minimize bias } \\
\text { - Ensuring the presence of an audit trail of study implementation }\end{array}$ & Objectivity \\
\hline
\end{tabular}

however, is rarely used in qualitative research related to regulatory issues. The remainder of this section briefly describes each methodology and its possible application to regulatory research.

Generic qualitative descriptive studies are the most common approach used in the literature, and Sandelowski's (2000) article remains one of the most highly cited qualitative methods papers. Generic approaches offer flexibility for studying regulation and regulatory issues, but because they lack a specific intent outside of describing a phenomenon, the applicability of the results may not be immediately apparent. Researchers choosing a generic descriptive approach for qualitative work are encouraged to make a good argument for their design choice as there may be better-suited methodologies that can improve study rigor and applicability.

Grounded theory studies are a good design choice when the end goal is to generate a theory from the data, rather than to use an individual's stories to describe the nuances of events or experiences (as in narrative analysis) or describe the lived experience of a phenomenon (as in phenomenology) (Charmaz, 2004, 2015). In regulation, there are multiple existing theories generated from nursing and other disciplines. Thus, researchers should ask themselves whether generating another theory is the necessary and appropriate means to the end goal of their study, or whether another qualitative method would be better suited to push the state of the literature forward.

Phenomenology is an in-depth approach to studying a phenomenon about lived experiences (Caelli, 2000; Norlyk \&
Harder, 2010; Starks \& Trinidad, 2007; van Manen, 2017; Willis, Sullivan-Bolyai, Knafl, \& Cohen, 2016). Generally, these studies have fewer participants than other qualitative methods, but they rely on multiple, longer interviews with each participant to capture the essence of the experience or event. It is easy for experienced reviewers to discern studies with too few participants when the author is simply calling it a phenomenology. For example, single, short duration interviews indicate the design choice is inappropriate for the study. A regulatory research study's aims would have to focus on understanding the lived experience of practicing under a specific regulation. Since regulations and their enforcement can change over time, it would be reasonable to expect multiple interviews were conducted from the same small sample size at multiple points in time, potentially over a long period. Those steps help generate in-depth findings and is where most phenomenological studies fall short on rigor and quality.

\section{Underutilized Qualitative Designs in Regulatory Research}

There are several qualitative designs that are underutilized in health profession regulatory research. This section highlights a few of them: (a) pragmatic qualitative studies, (b) case studies, (c) realist evaluations, and (d) narrative analyses.

Pragmatic qualitative studies are a subset of generic qualitative descriptive designs. Rooted in pragmatism, these studies seek to gain information that can be immediately transferred and applied to real world settings, whereas most generic qualitative designs simply seek to capture a phenomenon that is not well 
TABLE 2

\section{Qualitative Inquiry Frameworks and Potential Applications to Regulatory Studies}

\section{Qualitative Inquiry Disciplinary Roots Exemplar Question Framework

$\begin{array}{ll}\text { Autoethnography Literary arts } & \begin{array}{l}\text { It would be difficult to conduct an autoeth- } \\ \text { nography study about an individual's culture } \\ \text { affected by regulation since regulation affects } \\ \text { multiple people at the same time. }\end{array}\end{array}$

Case study Political and social - How did a regulation affect all stakesciences holders involved in a specific context?

- How were stakeholders from two different places (cases) affected by the same regulation?

Complexity theory Theoretical physics, biological sciences, ecology

- How do regulations affect the dynamics of complex adaptive systems?

Ethnography Anthropology

- How does group culture explain perspectives on regulations?

- How does the culture of a group explain behaviors resulting from regulation?

Ethnomethodology Sociology

- Within the boundaries of regulations (new or existing), how do people make sense of their everyday activities so as to behave in socially acceptable ways?

Grounded theory Social sciences methodology

- What theory, grounded in fieldwork, emerges from systematic comparative analysis of the implementation of regulations and how it affects stakeholders?

\begin{tabular}{|c|c|c|}
\hline Hermeneutics & $\begin{array}{l}\text { Linguistics, } \\
\text { philosophy, } \\
\text { literary criticism, } \\
\text { theology }\end{array}$ & $\begin{array}{l}\text { What are the conditions and content } \\
\text { under which a human act resulting } \\
\text { from or requiring a regulation took } \\
\text { place that makes it possible to interpret } \\
\text { its meaning? }\end{array}$ \\
\hline Heuristic inquiry & $\begin{array}{l}\text { Humanistic } \\
\text { psychology }\end{array}$ & $\begin{array}{l}\text { What is my experience of this phenom- } \\
\text { enon grounded in a specific regulation } \\
\text { and the essential experience of others } \\
\text { affected by the same regulation who } \\
\text { also experience this phenomenon } \\
\text { intensely? }\end{array}$ \\
\hline Narrative inquiry & $\begin{array}{l}\text { Social sciences, } \\
\text { literary criticism, } \\
\text { literary nonfiction }\end{array}$ & $\begin{array}{l}\text { What do human stories about the im- } \\
\text { pact of a regulation tell us about the ac- } \\
\text { tual effects versus the perceived } \\
\text { effects? }\end{array}$ \\
\hline $\begin{array}{l}\text { Pragmatism and } \\
\text { generic qualitative } \\
\text { inquiry }\end{array}$ & $\begin{array}{l}\text { Philosophy and } \\
\text { program } \\
\text { evaluation }\end{array}$ & $\begin{array}{l}\text { What are the practical consequences } \\
\text { and useful applications of what we can } \\
\text { learn about how a regulation has af- } \\
\text { fected an issue or problem? }\end{array}$ \\
\hline Realism & Philosophy & $\begin{array}{l}\text { What are the causal mechanisms that } \\
\text { explain how and why reality influenced } \\
\text { by a specific regulation unfolds as it } \\
\text { does in a particular context? }\end{array}$ \\
\hline
\end{tabular}

\section{Methods Note}

Multiple different stakeholders would be interviewed for a case study, and documentbased data would also serve as a data source. It is ideal for regional, state/provincial, national, or international studies.

The goal of the study is to capture these dynamics and highlight significant influences so that a better understanding results.

Data collection must also include observational data.

Data collection must also include observational data.

The end product of the study must either be a theory, tested theory, or conceptual model.

This approach is often linked with phenomenology. It requires close analysis of the use of language to describe experiences.

This approach has similar general limitations as autoethnography in which one risk of study implementation is that it becomes about only the researcher.

Interview guides are structured to elicit stories from individuals affected by a regulation or policy to understand their experiences with the regulatory phenomenon. It closely examines how people explain their experiences through stories.

A primary goal of the study is to develop action points local actors can immediately use to address a problem or issue caused by, resulting from, or demonstrating the need for a new/modified regulation.

This is a useful approach for foundational research that can help establish causal relationships between the implementation of a regulation or policy and its targeted outcomes. 


\section{Qualitative Inquiry Frameworks and Potential Applications to Regulatory Studies (continued)}

\begin{tabular}{|c|c|c|c|}
\hline $\begin{array}{l}\text { Qualitative Inquiry } \\
\text { Framework }\end{array}$ & Disciplinary Roots & Exemplar Question & Methods Note \\
\hline Phenomenology & Philosophy & $\begin{array}{l}\text { What is the meaning, structure, and es- } \\
\text { sence of the lived experience of this } \\
\text { phenomenon for this person or group } \\
\text { of people affected by a specific regula- } \\
\text { tion? Can also be reframed to focus on } \\
\text { those who may need a regulation to } \\
\text { improve safety or well-being. }\end{array}$ & $\begin{array}{l}\text { This is the only approach where less than } 16 \\
\text { participants is an acceptable sample size. }\end{array}$ \\
\hline Semiotics & Linguistics & $\begin{array}{l}\text { What regulatory signs (words and sym- } \\
\text { bols) carry and convey special meaning } \\
\text { in particular regulatory contexts? } \\
\text { What are the implications of those } \\
\text { signs for human beliefs, behaviors, and } \\
\text { interactions as governed by } \\
\text { regulations? }\end{array}$ & $\begin{array}{l}\text { Collaboration with a specialist in semiotics or } \\
\text { linguistics is important for producing rigor- } \\
\text { ous and trustworthy results. }\end{array}$ \\
\hline $\begin{array}{l}\text { Symbolic } \\
\text { interaction }\end{array}$ & Social psychology & $\begin{array}{l}\text { What common set of symbols and un- } \\
\text { derstandings have emerged to give } \\
\text { meaning to people's interactions within } \\
\text { a regulatory environment? }\end{array}$ & $\begin{array}{l}\text { Findings that illustrate relationships between } \\
\text { themes and categories using a conceptual } \\
\text { model enhance the rigor of these studies. }\end{array}$ \\
\hline Systems theory & Interdisciplinary & $\begin{array}{l}\text { How and why does this system func- } \\
\text { tion as it does as dictated by } \\
\text { regulations? } \\
\text { What are the system's boundaries and } \\
\text { interrelationships as established by the } \\
\text { regulation? } \\
\text { How do regulations affect perspectives } \\
\text { about how and why the system func- } \\
\text { tions as it does (or does not)? }\end{array}$ & $\begin{array}{l}\text { A key assumption here is that no system is } \\
\text { ever affected by a single regulation. These } \\
\text { studies can apply to new or existing studies, } \\
\text { as well as studies justifying the need for addi- } \\
\text { tional regulations. }\end{array}$ \\
\hline
\end{tabular}

understood, is not well described, and has no immediate transferability. A pragmatic qualitative study may be useful for studying how new regulations affect those subject to them during the early phases of implementation. A subsequent study goal may be to fine tune implementation processes to reduce any adverse effects. Since it has a specific intent to create immediately applicable findings, a pragmatic qualitative study offers more structure than other generic qualitative approaches when studying regulation.

Case studies are widely used in political science where regulatory issues are frequently studied (Anderson, Crabtree, Steele, \& McDaniel, 2005; Carolan, Forbat, \& Smith, 2015; Crowe et al., 2011; Elman, Gerring, \& Mahoney, 2016; Morgan, Pullon, Macdonald, McKinlay, \& Gray, 2017). A case study is useful for exploring or explaining a phenomenon that is poorly understood from a "big picture" perspective (Yin, 2018). Interviews (typically 30 to 50 with key stakeholders), documents, and observations can form the study data. Case studies produce comprehensive analyses and can include before and after perspectives, which may work well for exploring a state-level analysis of a regulatory change such as examining how stakeholders responded to the changes in nurse practitioner education, credentialing, and practice. Similarly, comparative case studies can examine how two different states responded to or did not respond to the same regulatory change.

Realist evaluations are a third example of underused qualitative study designs in regulatory research. A realist evaluation seeks to understand how reality influences a phenomenon (Anderson \& Hardwick, 2016; Busch, Koch, Clasen, Winkler, \& Vowinkel, 2017; Fletcher et al., 2016; Marchal, van Belle, van Olmen, Hoerée, \& Kegels, 2012; Porter, 2015; Westhorp, 2012, 2013). For studies of regulations and their effects, the practicality 
of this approach makes sense since qualitative studies should contribute to the evidence to support or change a regulation.

Finally, narrative analyses-a qualitative study design using storytelling techniques to capture participant experiences (Balon \& Rime, 2016; Macintyre Latta, Schnellert, Ondrik, \& Sasges, 2018; Sools, 2013; Spector-Mersel, 2011; Wolgemuth, 2014) —need an analytic approach that enables the researcher to examine the story progression and the factors that shape it, especially context. Narrative analysis can be an excellent way to compare contemporary and historical stakeholder perspectives around the legislative process or similar phenomena.

\section{Design Dictates the Analytic Approach}

A study's design is its foundation and determines how the researcher analyzes study data. A common mistake in qualitative submissions is that the coding approach is either not described or does not match the study design. It is also obvious to experienced reviewers when a researcher tried to retrofit a design to the findings of their qualitative study. Adhering to the scientific method, especially choosing the qualitative study design in advance, is critical for producing trustworthy results.

Researchers should beware of defaulting to general thematic analysis as their analytic plan. General analytic approaches tend to go with big picture or generic study designs (Caelli et al., 2003; Castro, Kellison, Boyd, \& Kopak, 2010; Griffith et al., 2017). They are not appropriate for phenomenological studies because they do not provide enough in-depth analysis to match the study's design and do not meet the philosophical underpinnings of the approach. Part of ensuring a rigorous and trustworthy qualitative study is making sure the design and analytic approach match.

Two other core concepts commonly confused in the analyses sections of qualitative studies are themes and categories. Morse (2008) published a simple editorial differentiating the two. A theme in qualitative research is something that runs through all the interviews as a persistent issue or experience.

A category occurs in qualitative research when codes can be grouped under a single title (Morse, 2008). They appear as distinct units of research data. Categories can often morph or transfer easily into quantifiably measurable variables in future quantitative studies, whereas themes are less transferable into a variable. Categories can also group together under certain themes, but they may also cross between themes due to how experiences of participants manifest themselves. Rigorous studies make clear differentiation between the two when presenting findings.

\section{Samples, Sampling, and Saturation}

Without the right sample to represent the phenomenon of interest, a qualitative study cannot achieve data saturation, meet its goals, or make a meaningful contribution to the literature. Regulatory research may face challenges regarding sample sizes that can truly achieve data saturation for presenting a trustworthy representation of the participants' experiences with a regulation. A unique challenge of both regulatory and health services research is sample sizes may be limited by the location of the study. For example, if a study about faculty experiences with a new educational regulation is conducted at a school with only eight faculty members, it may be difficult to find an appropriate qualitative design to achieve data saturation (not to mention ensuring participant confidentiality). Since sample size and data saturation are inherently linked, researchers need to develop sound methodological strategies to address these common issues inherent with small sample sizes (Malterud, Siersma, \& Guassora, 2015).

To achieve data saturation, researchers need to achieve both coding and thematic saturation. Coding saturation is commonly mistaken for thematic saturation (Hennink et al., 2017). Coding saturation occurs when no new codes appear during the analysis process or, with a larger sample size, only one or two additional codes appear unique to a participant's experience (MacPhail, Khoza, Abler, \& Ranganathan, 2015; Nelson, Burk, Knudsen, \& McCall, 2018; Saunders et al., 2018). Novice researchers may mistake this point in the analysis as having achieved saturation overall.

Thematic saturation, however, is the ultimate goal of any qualitative study and occurs when no new themes emerge from the data (Hennink et al., 2017; Lowe, Norris, Farris, \& Babbage, 2018; Saunders et al., 2018). The common experiences linking all participants will eventually clearly demarcate themselves from the data. Typically, most qualitative studies have three to five themes emerging from the data. More than five themes may occur with highly heterogenous samples or large sample sizes.

Recent methodological developments in the literature offer some new insights into qualitative sample sizes that can achieve saturation and are applicable across most qualitative study designs. Historically, most researchers would agree it took about 18 to 20 interviews for most studies to achieve saturation (Patton, 2015). Hennink et al. (2017), however, conducted an in-depth analysis of qualitative coding and thematic harmonization processes to provide better parameters for appropriate sample sizes, which can maximize the ability of a researcher to achieve data saturation. Their work built on two earlier studies by Guest, Bunce, and Johnson (2006) and Namey, Guest, McKenna, and Chen (2016). The team's findings suggest in most qualitative study designs - phenomenology being the exception — coding saturation occurs after nine interviews and thematic saturation occurs after between 16 and 24 interviews.

Hennink et al. (2017) found sample sizes needed to achieve data saturation ranged significantly and confirmed the intuitive recommendations posed by most qualitative methods textbooks. Even in the context of phenomenology, if participants are completing multiple interviews, then effectively the sample size comes closer to Hennink et al.'s (2017) recommendations. Nonetheless, the study authors strongly recommend additional 
replication of their work (as they did with the experiments of Guest et al. [2006] and Namey et al. [2016]) to further confirm their findings and solidify the evidence base around qualitative sample size recommendations. In the context of samples and sampling to achieve data saturation along with rigorous and trustworthy qualitative findings about a regulatory issue, planning to achieve a minimum sample size of 16 becomes a realistic and achievable goal in most cases.

What happens when conducting a study with a fixed sample size? If the sample size in a single site is not large enough, then one might argue that another site is needed for the study. A benefit of adding a second site in a regulatory study is the researcher has a greater probability of capturing common and institutionally differentiating experiences about the same phenomenon. Overall, that makes for a more useful contribution to the evidence base. If another site is not possible, then researchers can opt for two data collection points separated by a sufficient period to examine the long-term effects of a new or revised regulation. For example, in the case example where there were eight participants, two interviews with each participant at two different times creates a total interview sample size of 16 , thereby maximizing the opportunity to genuinely achieve data saturation and present meaningful findings.

Ensuring thematic saturation when the sample is naturally heterogeneous is another sampling issue. Sampling poses an interesting challenge when regulatory studies have multiple stakeholders. If there are enough stakeholders to obtain the range required for thematic saturation (16 to 24 participants), then a heterogeneous sample poses no threat to the trustworthiness of the findings. If a larger pool is available, however, then sampling to achieve coding saturation by a single identifier becomes an important consideration. To illustrate, if a study were to examine how changes to a state's nurse practitioner scope of practice affected care delivery in primary care settings, the study stakeholders might include nurse practitioners, primary care physicians, physician assistants, medical assistants, registered or practical nurses, and primary care office managers or similar administrators. Each role in primary care delivery is unique; to obtain sufficient data to clearly differentiate the experiences between each role, a researcher would need to get a minimum of nine participants in each role to achieve data saturation and a meaningful understanding of role distinctions and commonalities (Hennink et al., 2017; Lowe et al., 2018; Saunders et al., 2018). Thematic saturation would then truly reflect the experiences of all stakeholders involved, not just select groups. However, depending on the practice size, achieving the sample goal would require sampling from multiple practices. The benefit of this approach is contextual factors influencing experiences are more likely to emerge from the data.

Researchers, therefore, should aim to recruit a sample size to achieve data saturation. With the goal of data saturation at the forefront, researchers can be more confident in the trustworthiness of their results.

\section{Framing Findings}

Presenting qualitative findings should tell the story of the phenomenon of interest and represent the participants' thoughts and experiences. As Sandelowski and Leeman (2012) noted, qualitative health research should be useful to the reader and help contribute to the evidence base. For individuals with similar experiences as study participants, reading the findings should resonate with their own experience and they should find "truth" in the results.

Beginning the findings section of a qualitative study requires a strong opening sentence clearly stating the study focus in a way that captures readers' interest, which can be a challenge to do well. Experienced qualitative researchers often start the findings section with a paragraph framing the study in the context of who participated in the study, highlighting basic participant demographics, and including any study-specific demographics of importance to the specific study area. The second paragraph should describe the themes that emerged from the analysis and provide evidence-based definitions for them. This helps set up the presentation of the themes (using subheadings) and the supporting quotes. Common mistakes with presenting the findings include:

- Introducing quotes with a single sentence, rather than establishing the context of the quote and how it links to the theme

- Inserting overly long quotes to represent experiences or the phenomenon

- Failing to transition between quotes and the next paragraph without an explanatory or transition sentence

- Choosing quotes that do not represent the theme

- Inserting too many quotes

- Separating every quote, regardless of length (35 words or more should be in a separate paragraph), without integrating them into the paragraph for a seamless reading experience.

If the authors focus on telling the story of the participants with the phenomenon, avoiding the issues highlighted above becomes easier. It is more important to choose a truly representative quote of participant experiences than it is to have a large number.

\section{Choosing Quotes}

Throughout the data analysis process, certain quotes usually stand out as representative of participants' experiences and are important for articulately or succinctly explaining a phenomenon. Exemplar quotes should be noted when reading one-on-one or focus group transcripts for possible future inclusion in write-ups of study findings (Sandelowski \& Leeman, 2012). When many good quotes are present, it can be difficult to choose which one(s) to include. It is important to note selecting too many quotes will 
not improve the trustworthiness of the results and may dilute the impact of the study findings. Qualitative researchers should create systematic ways of keeping track of exemplar quotes so when telling the participants' stories, the researchers can represent their voices appropriately. Qualitative researchers are increasingly relying on software, such as Atlas.Ti, Dedoose, and NVivo, to organize the immense amount of data collected in interviews and/or focus groups. For most journals, authors should integrate quotes of fewer than 35 words into the manuscript while those longer than 35 words should be offset in a separate paragraph. Good quality qualitative manuscripts also do not leave quotes "hanging" in the text; rather, they conclude a paragraph or section with at least one sentence that summarizes the findings supported by the quote and its associated analysis.

\section{Managing Word Count Limitations}

It is very difficult to prepare a quality qualitative study when the word count limitation is less than 4,000 words. Many journals do not accommodate for the differences between qualitative and quantitative studies and apply the same word counts for quantitative studies as for qualitative studies. One strategy when word counts are limited is to place longer quotes in tables grouped thematically. While this may detract from the presentation of the story in the findings, it is an acceptable way to highlight the richness of representation that longer quotes provide while adhering to word count constraints. Journals with word counts greater than 4,000 words typically do not accept qualitative data organized into tables and expect the authors to integrate quotes into the manuscript.

\section{Avoiding Discussion Pitfalls and the Generalizability Trap}

Authors commonly make two mistakes in the discussion section of qualitative research papers. First, the discussion section is too brief because the authors left little room in the word count for a robust discussion of the findings. A good discussion section uses the first paragraph to summarize the findings from the study and how the findings are unique from the literature. The remainder of the discussion should relate the study's findings to the existing literature, highlighting where it supports the results from other studies and where it differs. Finally, the discussion section should always tie the content back to the original purpose of the study or research question. While findings are sometimes exciting and spawn new ideas for researchers, the study becomes less trustworthy and less useful for the reader if the content does not tie back to the original question.

The second common mistake in writing the discussion section is when authors assume the findings are generalizable to the broader population_-journal editors also often make this mistake when rejecting qualitative studies. Qualitative findings are only applicable to the local context where the study took place. They cannot be applied to other regional, state, national, or international populations unless it was the explicit intent of the original study design (Carminati, 2018). Aside from acknowledging this as a study limitation, a good technique is to highlight the importance of replicating the study with similar or more diverse populations affected by the same regulatory mechanism so the similarities and differences in experiences can be captured.

Finally, even though qualitative findings are not generalizable, there may still be implications for research, policy, practice, and education. Including a sentence or two about how the study's findings may influence each factor provides useful direction for others seeking to replicate the study in different contexts or with populations affected by the same regulation. In addition, identification of potential variables for future quantitative studies can also result from a good quality qualitative study. Offering suggestions for realistic, existing, measureable variables that might be sensitive to the effects of a regulation is useful to include in the discussion section.

\section{Conclusions}

Qualitative research provides the opportunity to understand the development and implementation of regulations and policies, as well as the experiences of stakeholders. Only when we understand the nuances of the experiences those affected by regulations have (or do not have) can we generate evidence for when and how regulations are working. When researchers generate enough studies about the same regulation, a qualitative meta-synthesis becomes the next step so multiple voices from different contexts subject to the same regulations can be heard. Those findings become generalizable and can further inform adjustments to the regulation or arguments for or against renewals.

However, to help create the impetus for change or maintenance of the status quo, the quality of these studies needs to improve in nursing and health profession regulation. This article can serve as a useful guide for improving the quality of research methodology and dissemination.

\section{References}

Anderson, R. A., Crabtree, B. F., Steele, D. J., \& McDaniel, R. R. (2005). Case study research: The view from complexity science. Qualitative Health Research, 15(5), 669-685. https://doi. org/10.1177/1049732305275208

Anderson, R., \& Hardwick, R. (2016). Realism and resources: Towards more explanatory economic evaluation. Evaluation, 22(3), 323-341. https://doi.org/10.1177/1356389016652742

Balon, S., \& Rime, B. (2016). Lexical profile of emotional disclosure in socially shared versus written narratives. Journal of Language and Social Psychology, 35(4), 345-373. https://doi. org/10.1177/0261927X15603425 
Bartlam, B., Waterfield, J., Bishop, A., Holden, M. A., Barlas, P., Ismail K. M., ... Foster, N. E. (2016). The role of qualitative research in clinical trial development: The EASE Back Study. Journal of Mixed Methods Research, 12(3), 325-343. https://doi. org/10.1177/1558689816656740

Blackman, T., Wistow, J., \& Byrne, D. (2013). Using qualitative comparative analysis to understand complex policy problems. Evaluation, 19(2), 126-140. https://doi.org/10.1177/1356389013484203

Bochner, A. P. (2018). Unfurling rigor: On continuity and change in qualitative inquiry. Qualitative Inquiry, 24(6), 359-368. https://doi. org/10.1177/1077800417727766

Bradley, E. H., Curry, L. A., \& Devers, K. J. (2007). Qualitative data analysis for health services research: Developing taxonomy, themes, and theory. Health Services Research, 42(4), 1758-1772. https://doi. org/10.1111/j.1475-6773.2006.00684.x

Busch, C., Koch, T., Clasen, J., Winkler, E., \& Vowinkel, J. (2017). Evaluation of an organizational health intervention for low-skilled workers and immigrants. Human Relations, 70(8), 994-1016. https://doi. org $/ 10.1177 / 0018726716682308$

Caelli, K. (2000). The changing face of phenomenological research: Traditional and American phenomenology in nursing. Qualitative Health Research, 10(3), 366-377. https://doi org/10.1177/104973200129118507

Caelli, K., Ray, L., \& Mill, J. (2003). 'Clear as mud': Toward greater clarity in generic qualitative research. International Journal of Qualitative Methods, 2(2), 1-13. https://doi.org/10.1177/160940690300200201

Carminati, L. (2018). Generalizability in qualitative research: A tale of two traditions. Qualitative Health Research. Advance online publication. https://doi.org/10.1177/1049732318788379

Carolan, C. M., Forbat, L., \& Smith, A. (2015). Developing the DESCARTE Model: The design of case study research in health care. Qualitative Health Research, 26(5), 626-639. https://doi. org/10.1177/1049732315602488

Carter, S. M., \& Little, M. (2007). Justifying knowledge, justifying method, taking action: Epistemologies, methodologies, and methods in qualitative research. Qualitative Health Research, 17(10), 1316-1328. https://doi.org/10.1177/1049732307306927

Castro, F. G., Kellison, J. G., Boyd, S. J., \& Kopak, A. (2010). A methodology for conducting integrative mixed methods research and data analyses. Journal of Mixed Methods Research, 4(4), 342-360. https:// doi.org/10.1177/1558689810382916

Chapple, A., \& Ziebland, S. (2018). Methodological and practical issues in cross-national qualitative research: Lessons from the literature and a comparative study of the experiences of people receiving a diagnosis of cancer. Qualitative Health Research, 28(5), 789-799. https://doi. org/10.1177/1049732317736284

Charmaz, K. (2004). Premises, principles, and practices in qualitative research: Revisiting the foundations. Qualitative Health Research, 14(7), 976-993. https://doi.org/10.1177/1049732304266795

Charmaz, K. (2015). Teaching theory construction with initial grounded theory tools: A reflection on lessons and learning. Qualitative Health Research, 25(12), 1610-1622. https://doi.org/10.1177/ 1049732315613982

Chiumento, A., Rahman, A., Machin, L., \& Frith, L. (2017). Mediated research encounters: Methodological considerations in cross-language qualitative interviews. Qualitative Research. Advance online publication. https://doi.org/10.1177/1468794117730121

Croot, E. J., Lees, J., Grant, G., Barbour, R. S., Bradby, H., Croot, E. J., ... Poon, M. K.-L. (2011). Evaluating standards in cross-language research: A critique of Squires' criteria. International Journal of Nursing Studies, 48(8), 1002-1011. https://doi.org/10.1016/j. ijnurstu.2011.04.007
Crowe, S., Cresswell, K., Robertson, A., Huby, G., Avery, A., \& Sheikh, A. (2011). The case study approach. BMC Medical Research Methodology, 11(1), 100. https://doi.org/10.1186/1471-2288-11-100

Elman, C., Gerring, J., \& Mahoney, J. (2016). Case study research: Putting the quant into the qual. Sociological Methods E Research, 45(3), 375-391. https://doi.org/10.1177/0049124116644273

Evans-Agnew, R. A., Johnson, S., Liu, F., \& Boutain, D. M. (2016). Applying critical discourse analysis in health policy research: Case studies in regional, organizational, and global health. Policy, Politics E Nursing Practice, 17(3), 136-146. https://doi. org $/ 10.1177 / 1527154416669355$

Fletcher, A., Jamal, F., Moore, G., Evans, R. E., Murphy, S., \& Bonell, C. (2016). Realist complex intervention science: Applying realist principles across all phases of the Medical Research Council framework for developing and evaluating complex interventions. Evaluation, 22(3), 286-303. https://doi.org/10.1177/1356389016652743

Griffith, D. M., Shelton, R. C., \& Kegler, M. (2017). Advancing the science of qualitative research to promote health equity. Health Education \& Behavior, 44(5), 673-676. https://doi. org/10.1177/1090198117728549

Guest, G., Bunce, A., \& Johnson, L. (2006). How many interviews are enough? Field Methods, 18(1), 59-82. https://doi. org/10.1177/1525822X05279903

Hennink, M. M., Kaiser, B. N., \& Marconi, V. C. (2017). Code saturation versus meaning saturation: How many interviews are enough? Qualitative Health Research, 27(4), 591-608. https://doi. org/10.1177/1049732316665344

Krefting, L. (1991). Rigor in qualitative research: The assessment of trustworthiness. The American Journal of Occupational Therapy, 45(3), 214-222

Lincoln, Y. S., Gonzalez y Gonzalez, E. M., \& Aroztegui Massera, C. (2016). "Spanish is a loving tongue ... ": Performing qualitative research across languages and cultures. Qualitative Inquiry, 22(7), 531-540. https://doi.org/10.1177/1077800416636148

Lincoln, Y. S., \& Guba, E. G. (1985). Naturalistic inquiry. Newbury Park, CA: Sage Publications.

Lowe, A., Norris, A. C., Farris, A. J., \& Babbage, D. R. (2018). Quantifying thematic saturation in qualitative data analysis. Field Methods, 30(3), 191-207. https://doi.org/10.1177/1525822X17749386

Macintyre Latta, M., Schnellert, L., Ondrik, K., \& Sasges, M. (2018). Modes of being: Mobilizing narrative inquiry. Qualitative Inquiry. Advance online publication. https://doi org/10.1177/1077800418786309

MacKenzie, C. A. (2015). Filtered meaning: Appreciating linguistic skill, social position and subjectivity of interpreters in cross-language research. Qualitative Research, 16(2), 167-182. https://doi. org/10.1177/1468794115569564

MacPhail, C., Khoza, N., Abler, L., \& Ranganathan, M. (2015). Process guidelines for establishing intercoder reliability in qualitative studies. Qualitative Research, 16(2), 198-212. https://doi. org/10.1177/1468794115577012

Majid, U., \& Vanstone, M. (2018). Appraising qualitative research for evidence syntheses: A compendium of quality appraisal tools. Qualitative Health Research. Advance online publication. https://doi. org/10.1177/1049732318785358

Malterud, K., Siersma, V. D., \& Guassora, A. D. (2015). Sample size in qualitative interview studies: Guided by information power. Qualitative Health Research, 26(3), 1753-1760. https://doi. org/10.1177/1049732315617444

Marchal, B., van Belle, S., van Olmen, J., Hoerée, T., \& Kegels, G. (2012). Is realist evaluation keeping its promise? A review of published empirical studies in the field of health systems research. Evaluation, 18(2), 192-212. https://doi. org/10.1177/1356389012442444 
Morgan, S. J., Pullon, S. R. H., Macdonald, L. M., McKinlay, E. M., \& Gray, B. V. (2017). Case study observational research: A framework for conducting case study research where observation data are the focus. Qualitative Health Research, 27(7), 1060-1068. https://doi. org/10.1177/1049732316649160

Morse, J. M. (2008). Confusing categories and themes. Qualitative Health Research, 18(6), 727-728. https://doi. org/10.1177/1049732308314930

Morse, J. M. (2015). Critical analysis of strategies for determining rigor in qualitative inquiry. Qualitative Health Research, 25(9), 1212-1222. https://doi.org/10.1177/1049732315588501

Namey, E., Guest, G., McKenna, K., \& Chen, M. (2016). Evaluating bang for the buck. American Journal of Evaluation, 37(3), 425-440. https://doi.org/10.1177/1098214016630406

Nelson, L. K., Burk, D., Knudsen, M., \& McCall, L. (2018). The Future of Coding. Sociological Methods \& Research. Advance online publication. https://doi.org/10.1177/0049124118769114

Norlyk, A., \& Harder, I. (2010). What makes a phenomenological study phenomenological? An analysis of peer-reviewed empirical nursing studies. Qualitative Health Research, 20(3), 420-431. https://doi. org/10.1177/1049732309357435

Patton, M. Q. (2015). Qualitative research and evaluation methods (4th ed.). Thousand Oaks, CA: Sage.

Porter, S. (2015). The uncritical realism of realist evaluation. Evaluation, 21(1), 65-82. https://doi.org/10.1177/1356389014566134

Sandelowski, M. (2000). Whatever happened to qualitative description? Research in Nursing \& Health, 23(4), 334-340.

Sandelowski, M., \& Leeman, J. (2012). Writing usable qualitative health research findings. Qualitative Health Research, 22(10), 1404-1413. https://doi.org/10.1177/1049732312450368

Santos, H. P. O., Black, A. M., \& Sandelowski, M. (2014). Timing of translation in cross-language qualitative research. Qualitative Health Research, 25(1), 134-144. https://doi. org/10.1177/1049732314549603

Saunders, B., Sim, J., Kingstone, T., Baker, S., Waterfield, J., Bartlam, B., ... Jinks, C. (2018). Saturation in qualitative research: Exploring its conceptualization and operationalization. Quality \& Quantity, 52(4), 1893-1907. https://doi.org/10.1007/s11135-017-0574-8

Sools, A. (2013). Narrative health research: exploring big and small stories as analytical tools. Health (London, England: 1997), 17(1), 93-110. https://doi.org/10.1177/1363459312447259

Spector-Mersel, G. (2011). Mechanisms of selection in claiming narrative identities: A model for interpreting narratives. Qualitative Inquiry, 17(2), 172-185. https://doi.org/10.1177/1077800410393885

Squires, A. (2008). Language barriers and qualitative nursing research: Methodological considerations. International Nursing Review, 55(3), 265-273. https://doi.org/10.1111/j.1466-7657.2008.00652.x

Squires, A. (2009). Methodological challenges in cross-language qualitative research: A research review. International Journal of Nursing Studies, 46(2), 277-287. https://doi.org/10.1016/j.ijnurstu.2008.08.006

Starks, H., \& Trinidad, S. B. (2007). Choose your method: A comparison of phenomenology, discourse analysis, and grounded theory. Qualitative Health Research, 17(10), 1372-1380. https://doi. org/10.1177/1049732307307031

Suurmond, J., Woudstra, A., \& Essink-Bot, M.-L. (2016). The interpreter as co-interviewer: The role of the interpreter during interviews in cross-language health research. Journal of Health Services Research $\mathcal{E}$ Policy, 21(3), 172-177. https://doi.org/10.1177/1355819616632020

Temple, B. (2002). Crossed wires: interpreters, translators, and bilingual workers in cross-language research. Qualitative Health Research, 12(6), 844-854
Tracy, S. J. (2010). Qualitative quality: Eight "big-tent" criteria for excellent qualitative research. Qualitative Inquiry, 16(10), 837-851. https://doi.org/10.1177/1077800410383121

Tufford, L., \& Newman, P. (2012). Bracketing in qualitative research. Qualitative Social Work, 11(1), 80-96. https://doi. org/10.1177/1473325010368316

van Manen, M. (2017). Phenomenology in its original sense. Qualitative Health Research, 27(6), 810-825. https://doi. org/10.1177/1049732317699381

Vandermause, R., Barg, F. K., Esmail, L., Edmundson, L., Girard, S., \& Perfetti, A. R. (2016). Qualitative methods in patient-centered outcomes research. Qualitative Health Research, 27(3), 434-442. https:// doi.org/10.1177/1049732316668298

Westhorp, G. (2012). Using complexity-consistent theory for evaluating complex systems. Evaluation, 18(4), 405-420. https://doi. org/10.1177/1356389012460963

Westhorp, G. (2013). Developing complexity-consistent theory in a realist investigation. Evaluation, 19(4), 364-382. https://doi. org/10.1177/1356389013505042

Willis, D. G., Sullivan-Bolyai, S., Knafl, K., \& Cohen, M. Z. (2016). Distinguishing features and similarities between descriptive phenomenological and qualitative description research. Western Journal of Nursing Research, 38(9), 1185-204. https://doi. org/10.1177/0193945916645499

Wolgemuth, J. R. (2014). Analyzing for critical resistance in narrative research. Qualitative Research, 14(5), 586-602. https://doi. org/10.1177/1468794113501685

Wong, J. P.-H., \& Poon, M. K.-L. (2010). Bringing translation out of the shadows: Translation as an issue of methodological significance in cross-cultural qualitative research. Journal of Transcultural Nursing, 21(2), 151-158. https://doi.org/10.1177/1043659609357637

Yardley, S. J., Watts, K. M., Pearson, J., \& Richardson, J. C. (2014). Ethical issues in the reuse of qualitative data: Perspectives from literature, practice, and participants. Qualitative Health Research, 24(1), 102-113. https://doi.org/10.1177/1049732313518373

Yin, R. K. (2018). Case study research E applications (6th ed.). Thousand Oaks, CA: Sage.

Allison Squires, PhD, RN, FAAN, is an associate professor at the Meyers College of Nursing, New York University. Caroline Dorsen, PhD, FNP, RN, is an assistant professor at the Meyers College of Nursing New York University. 


\section{Qualitative Research in Nursing and Health Professions Regulation}

\section{Objectives}

- Explain the importance of qualitative research for studies about regulatory issues in nursing.

- Discuss the core concepts of qualitative research.

- Describe common methodological challenges researchers can encounter when conducting qualitative research on professional regulatory issues.

- Identify solutions that can enhance the quality, rigor, and trustworthiness of the findings for regulatory studies.

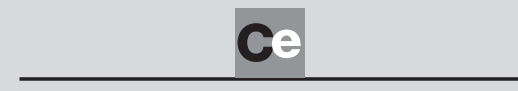

\section{CE Posttest}

If you reside in the United States and wish to obtain 1.5 contact hour of continuing education (CE) credit, please review these instructions.

\section{Instructions}

Go online to take the posttest and earn CE credit:

Members - www.ncsbninteractive.org (no charge)

Nonmembers - www.learningext.com (\$15 processing fee)

If you cannot take the posttest online, complete the print form and mail it to the address (nonmembers must include a check for $\$ 15$, payable to NCSBN) included at the bottom of the form.

\section{Provider accreditation}

The NCSBN is accredited as a provider of CE by the Alabama State Board of Nursing.

The information in this CE activity does not imply endorsement of any product, service, or company referred to in this activity.

Contact hours: 1.5

Posttest passing score is $75 \%$.

Expiration: October 2021

\section{Posttest}

Please circle the correct answer.

1. Why are health professions regulated?

a. Local and national governmental oversight through health professions regulation is needed for professional practice.

b. Health professions are regulated in order to avoid a risk of harm to the public.

c. Congress mandates that all professions are regulated.

d. Both $a$ and $b$

2. What is the value of qualitative research to studies regarding nursing regulation?

a. There are not enough studies to determine the effectiveness of qualitative research yet.

b. Quantitative research is more critical because it provides both exploratory and explanatory data.

c. Qualitative research can play a vital role in ensuring that the stakeholder's voice is represented and their experiences inform the evaluation of regulations and their associated policies.

d. None of the above

3. Less than $5 \%$ of published studies in the Journal of Nursing Regulation's last decade were qualitative.

a. True

b. False

4. On its own and with sufficient replication, qualitative research can provide supporting evidence for the , or

\section{of regulations.}

a. Identification, modification, or abolition

b. Creation, modification, or elimination

c. Oversight, enforcement, or evaluation

d. Creation, development, or destruction

5. Which core concept of qualitative research is defined as how the researcher establishes the trustworthiness of the findings presented?

a. Rigor

b. Bias

c. Data saturation

d. Reliability

6. Part of ensuring rigor in any research study is addressing the central concern about the possible influence of ideas and opinions of the researchers conducting the research study through the concept of

a. Data saturation

b. Trustworthiness

c. Bias

d. None of the above
7. An important concept in qualitative research because it, in effect, tells the researcher when no more interviews are needed and that data collection can end is:

a. Termination

b. Content closure

c. Conclusion

d. Data saturation

8. For research findings to be they need to not only meet the four criteria associated with research rigor, but they should also have a common truth to them that resonates with those who have had similar experiences.

a. Rigorous

b. Trustworthy

c. Unbiased

d. Credible

9. A qualitative approach to research is a type of study design in and of itself.

a. True

b. False

10. Which type of qualitative study design is rarely used in qualitative research related to regulatory issues?

a. Grounded theory

b. Phenomenology

c. Ethnography

d. Generic qualitative descriptive

11. What argument could a regulatory researcher make for a generic qualitative descriptive design choice?

a. The applicability of the results is immediately apparent and translatable into the real world.

b. The end goal of the study is to generate a theory from the data.

c. The study must describe the lived experience of a phenomenon.

d. Generic approaches offer flexibility for studying regulation and regulatory issues.

Match the type of underutilized qualitative design in regulatory research with its corresponding description:

12. Pragmatic qualitative studies

13. Case studies

14. Realist evaluations

15. Narrative analysis

a. Might work well exploring a state level analysis of a regulatory change

b. A way to compare contemporary and historical stakeholder perspectives around the legislative process or similar phenomena

c. Might be useful for studying how new regulations have affected those subject to them during the early phases of implementation

d. Contributes to the evidence to support or change a regulation 
16. What is the goal for sample size in a qualitative research study about a regulatory issue?

a. Recruit a sample size that will achieve data saturation.

b. Aim for a heterogeneous sample.

c. Plan to achieve a minimum sample size of 8 as a realistic and achievable goal in most cases.

d. Sample size has no impact on regulatory research.

17. To begin a findings section of a qualitative study, a should clearly state the focus of the study in a way that captures the reader's interest.

a. Long quote

b. Strong opening sentence

c. Theme

d. Phenomenon

18. Why are quotes important tools for framing a study's findings?

a. Representative of participants' experiences

b. Improve the trustworthiness of results

c. Articulately or succinctly explain a phenomenon

d. All of the above

19. Choose the mistake(s) that authors commonly make in the discussion section of qualitative research papers:

a. The discussion section may end up too "thin" because the authors have left no room in the word count for a robust discussion of the findings

b. The discussion section uses the first paragraph to summarize the findings from the study and how they are unique from the literature

c. The authors assume the findings are generalizable to the broader population.

d. a and c

20. Which of the following statements is true about qualitative discussion sections?

a. They should include all findings, even if the content does not tie back to the original research question.

b. They can provide useful direction for others seeking to replicate the study in different contexts or with populations affected by the same regulations.

c. Suggestions for realistic, existing, measurable variables that might be sensitive to the effects of a regulation cannot be useful for a qualitative study focused on regulation.

d. Qualitative findings can always be applied to other regional, state, national, or international populations.

\section{Evaluation Form (required)}

1. Rate your achievement of each objective from 5 (high/excellent) to 1 (low/poor).

- Explain the importance of qualitative research for studies about regulatory issues in nursing.

\begin{tabular}{lllll}
1 & 2 & 3 & 4 & 5 \\
\hline
\end{tabular}

- Discuss the core concepts of qualitative research.

\begin{tabular}{lllll}
1 & 2 & 3 & 4 & 5 \\
\hline
\end{tabular}

- Describe common methodological challenges researchers can encounter when conducting qualitative research on professional regulatory issues.

$\begin{array}{lllll}1 & 2 & 3 & 4 & 5\end{array}$

- Identify solutions that can enhance the quality, rigor, and trustworthiness of the findings for regulatory studies.

\begin{tabular}{lllll}
1 & 2 & 3 & 4 & 5 \\
\hline
\end{tabular}

2. Rate each of the following items from $\mathbf{5}$ (strongly agree) to 1 (strongly disagree):

- Were the authors knowledgeable about the subject?
1
2
3
4
5

- Were the methods of presentation (text, tables, figures, etc.) effective?

$\begin{array}{llll}1 & 2 & 3 & 4\end{array}$

- Was the content relevant to the objectives?

$\begin{array}{lllll}1 & 2 & 3 & 4 & 5\end{array}$

- Was the article useful to you in your work?

$\begin{array}{llllll}1 & 2 & 3 & 4 & 5\end{array}$

- Was there enough time allotted for this activity?

\begin{tabular}{lllll}
1 & 2 & 3 & 4 & 5 \\
\hline
\end{tabular}

Comments:

5

\section{(1)}

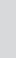

(1)

Please print clearly

Name

Mailing address

Street

City

State Zip

Home phone

Business phone

Fax

E-mail

Method of payment (check one box)

$\square$ Members (no charge)

$\square$ Nonmembers (must include a check for $\$ 15$ payable to NCSBN)

PLEASE DO NOT SEND CASH.

Mail completed posttest, evaluation form, registration form, and payment to:

NCSBN

111 East Wacker Drive

Suite 2900

Chicago, IL 60601-4277

Please allow 4 to 6 weeks for processing. 